\title{
Investigating Antecedents and Development of Trust in Ridesharing Platform: A Case from China
}

\author{
Ying Bao \\ University of International \\ Business and Economics \\ $\underline{201710411216 @ \text { uibe.edu.cn }}$
}

\author{
Xusen Cheng \\ University of International \\ Business and Economics \\ xusen.cheng@uibe.edu.cn
}

\author{
Douglas Druckenmiller \\ Western Illinois University \\ DA-Druckenmiller@wiu.edu
}

\begin{abstract}
Trust is playing an important role in the sharing economy-driven business. However, little research has been conducted measuring trust as a dynamic process in the sharing economy era. This research is a preliminary exploration investigating trust antecedents and the dynamic development of clients' trust in ridesharing platforms. We used 102 two-stage interviews collected from clients of a major Chinese ridesharing platform. Then we conducted a qualitative content analysis and proposed a theoretical model based on literature and data analysis. We found that antecedents of trust in two stages are different. Personality-based beliefs and cognition-based beliefs are the main antecedents of initial trust, while knowledge-based beliefs, institution-based beliefs, and calculus-based beliefs are the main antecedents of ongoing trust. These findings could help us understand how trust evolves over time and enable us to explore several viewpoints on ridesharing platforms.
\end{abstract}

\section{Introduction}

Information and communication technology (ICT) has enabled the rise of collaborative consumption, which is also called as "sharing economy". With the popularity of ICT, online sharing marketplaces are growing at a rapid rate, especially in travel and tourism services [1]. In recent years, a new type of sharing economy-driven business model, which is known as ridesharing, has emerged. Ridesharing is mainly associated with transportation services [2]. In a ridesharing trading process, people seek low-cost transportation services. Ridesharing clients have direct interaction and communication with the service providers via mobile phone. From this interaction, the ridesharing platform matches a suitable driver for the client and brings strangers together. To complete the trading process, trust plays a significant role and helps communication. Since trading with strangers involves information asymmetry, many factors influence trust and the trust intention among traders [3]. As a result, we intend to have a deeper understanding of clients' trust towards the ridesharing platform in this study.

Previous studies have found that trust antecedents vary in different types of business models and many factors have been proved to influence trust [4] [5]. Studies about trust antecedents based on the new business model, ridesharing, are limited, and they have not defined the evolving process of trust over time [6]. Nevertheless, trust building is a dynamic process and trust will be influenced by many factors as time goes by. In addition, unlike the traditional vender-client relationship, the primary vender in our research is information technology (IT). Thus, we will also incorporate some perceived technological attributes of the ICT as some factors to understand trust development. Therefore, we tend to have a deeper understanding of clients' trust toward online ridesharing platforms and the evolving processes in ridesharing. We attempt to answer the following questions in this paper:

Research question 1: What factors lead to the clients' trust in ridesharing platforms in initial stage and ongoing stage?

Research question 2: How does trust develop from initial stage to ongoing stage?

In detail, we conducted a qualitative method in this study. For the first research question, we referred to previous studies to find the overall antecedents of trust. Then we made a comparison of initial trust antecedents and ongoing trust antecedents, followed by identifying specific trust antecedents for the two stages. For the second research question, we tent to refer to the literature and made a combination of technology acceptance model (TAM) and rational choice theory (RCT) to investigate the dynamic process of trust development from initial stage to ongoing stage.

The overall structure of the paper is five parts. In the first part, the paper gives a brief overview of the relationship between ridesharing and trust. In the 
second part, we put forward the literature and theoretical background, attaching importance to theory-oriented perspectives of online trust in ridesharing. Part three introduces our research method and the data we collected. Part four presents our research model and hypotheses. In the last part, we conclude the paper with a summary of the research and its contribution.

\section{Literature review}

Trust determines buyer-seller relationships, especially in many establishing or early-stage partnerships and plays a critical role in long-term relationships [7]. Instead of remaining fixed, trust develops from an initial stage to an ongoing stage in a dynamic process. In this section, we present the relevant background literature for our research.

\subsection{Trust antecedents}

According to previous studies, trust is "a psychological state comprising the intention to accept vulnerability based upon positive expectations of the intentions or behavior of another" [8]. Trust is related to many cognitive and behavioral intention subfactors. As for the antecedents of trust, researchers have identified several trust antecedents and corresponding types of trust: knowledge-based trust [9], institutionbased trust, calculative-based trust, cognition-based trust, and personality-based trust [10].

Knowledge-based trust derives from familiarity with the e-vendor [11] [12]. Familiarity with the evendor may reduce social uncertainty and increase the trust relationship. In traditional e-commerce situations, familiarity corresponds to how well the clients comprehend the procedures of the platform, including when and how to enter user information and how to place an order. Trust may develop over time with the accumulation of trust-relevant knowledge resulting from experience with the other party. Accordingly, the accumulated trust-relevant knowledge and successful experience lead to higher knowledge-based trust in ridesharing platforms. In this research, a client's familiarity with an e-vendor is considered as well as a client's familiarity with the ridesharing platform.

Institution-based trust derives from clients' sense of security from safety nets, guarantees, or other structures in the trading context, including situational normality and structural assurance [13]. Situation normality assures people that everything in the transaction process is based on a normal situation and everything is as it ought to be. Structural assurance means that if a transaction is based on a series of safety nets, such as legal recourse or guarantees, clients may attain a high level of trust in the trading process. As institution-based trust proposes, the trust relationship will be increased as a result of a normal and typical situation or safety nets [14].

According to calculative-based trust, trust is derived from an economic analysis of ongoing relationships, the higher cost of crime means less criminality and more trustworthiness [15]. Based on this assumption, people are rational and calculative; they act in their best self-interest and seek maximum personal utility. In these circumstances, rational clients believe that platforms have nothing to gain by breaking their trust relationship.

Cognition-based trust is mainly concentrated on trust building through first impressions rather than personal interactions. In the absence of first-hand information, many clients may assess a person's trustworthiness by observation. In this context, trust may be over-inflated.

Personality-based trust refers to the tendency to trust or not to trust others. It is based on the belief that others are reliable before any experience or trading has happened [16], which is important for inexperienced online consumers [17]. Later, as people have more interaction with each other, their trustworthiness will be more influenced by the interaction itself and the trust propensity will be less important in the building of trust.

In this study, we focus on these factors as antecedents of initial trust and ongoing trust.

\subsection{Distinction between initial trust and ongoing trust}

Trust is not a steady state during the whole trading process; however, it is perceived as a dynamic process and plays an important role in long-term relationships [18]. The dynamic nature of trust accounts for the distinction between initial trust and ongoing trust [19].

At the initial stage of exposure to new business models, clients have no prior interaction or first-hand experience with the platform or online e-vendor. Trust is mostly built on first impressions and a client's own personality. We posit that initial trust involves the willingness to trust others without prior knowledge. As a result, personality-based trust and cognition-based trust are the two primary characteristics in the initial stage, which is considered as initial trust in our research.

However, unlike initial trust, ongoing trust is usually modified according to experience or interaction with others. Thus, ongoing trust in our study results from observing actual interactions and is a positive 
belief based on first-hand experience with the platform or online e-vendor.

\subsection{Trust in sharing economy}

Trust and its antecedents have been studied by many scholars in previous studies. In traditional transactions and E-Commerce, trust is created for the following reasons: (1) real product or online pictures, which are visual, (2) frequent interactions with the same seller, (3) evaluation mechanisms, and (4) established brand names [2]. However, in the sharing economy and online trading processes, the traders are complete strangers and know little about the other's characteristics [15][21]. Consumers rarely trade frequently with the same retailers or service providers [21]. Trust is crucial in such transactional relationships and has been categorized by scholars in a variety of ways. While some researchers have explored clients' trust in the drivers of ridesharing platforms, in this research, we emphasize the importance of trust between clients and platforms and the dynamic process of trust development from initial to ongoing stage.

\subsection{Rational choice theory ( RCT )}

Rational choice theory (RCT), defined by Paternoster and Simpson [22], is a theory from criminology. The theory proposes that people are rational in maximizing their self-interest [23]. By considering the cost-benefit analysis of individual offenders and the organizational context, people will adjust their corporate deviant behaviors [24]. According to this theory, we assume that clients are rational individuals who possess the ability to analyze costs and benefits. Similarly, the platform manager will also assess the costs and benefits of deviant behavior in order to regulate platform behavior.

\section{Methods and research design}

We chose a case study approach to explore the factors of clients' trust in ridesharing platforms. Indepth interviews were conducted to collect data for this research. Nvivo11 was used to conduct our coding process in the qualitative analysis and a comparison of the two-stage trust was conducted after the coding analysis. We will collect additional quantitative data using surveys or other approaches in our future research.

\subsection{Case study and data collection}

To explore clients' real feelings about trust in ridesharing platforms, we choose a well-known Chinese ridesharing platform as our subject platform and conducted 102 in-depth interviews with the clients in two stages.

Fifty-one interviews were conducted in year1 comprised the initial stage and fifty-one interviews in year 2 comprised the ongoing stage. Between the two interviews, ridesharing platforms have developed to a more mutual stage. Moreover, more news about ridesharing has been published and people paid more attention on ridesharing platforms. At the same time, a policy on regulating ridesharing platforms has been proposed by Chinese government. All these factors have been proved to influence clients' trust in the ridesharing platform. Thus, we developed several questions based on previous research and interviewed the clients who use the ridesharing platform to order the service. For the case study, we recorded every interview and transcribed them.

\subsection{Data analysis and coding}

In this section, we present the empirical evidence to support our study of trust antecedents. We coded the transcripts in Nvivo11 using the variables referred to in the transcripts as a node in the software to identify the trust antecedents and how the factors influence trust in the trading process [25]. Fig 1 illustrates several frequent words in the transcripts in the form of a word cloud. In the coding process, we first extracted the important individual case and the original statement about trust. Then we conceptualized the definition of initial concepts and categorized the same concept into a construct. A justification of the trust factors of the transaction process and some interview examples are shown in Table 1.

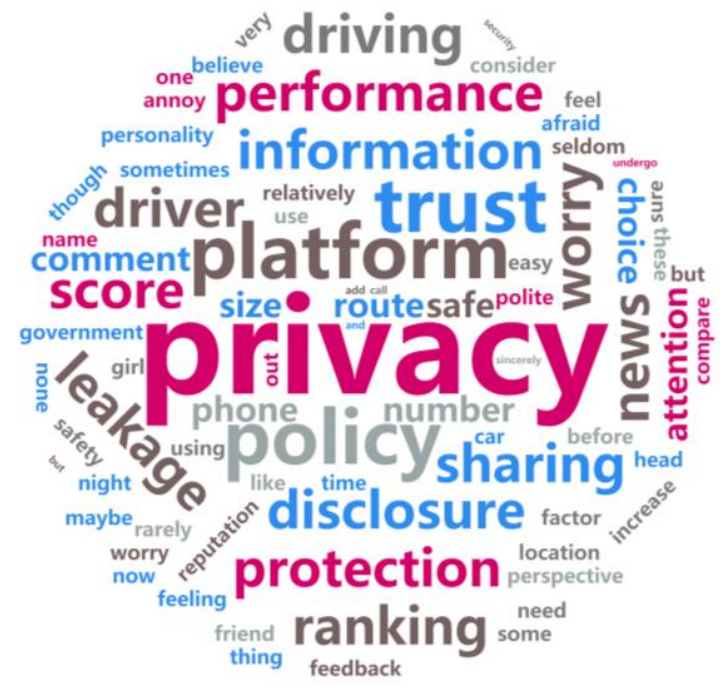




\section{Figure 1. Indicative word cloud of transcripts}

As is shown in table 1, we conducted several steps in the open coding process [26]. In the first step, we selected all the important content in our interviews and divided the original source into different stories about different trust antecedents. Then we simplified the original statement and came up with a special definition for every statement and labeled them with '(ax)'. We reclassify the specific appearance and developed a conceptualization from the definition and labeled the new classification with '(Ax)'. Next, we developed every conceptualization into a more rigorous description which covers several similar definitions, which are composed of several trust antecedents that impact clients' trust on the ridesharing platform. Then we labeled each category of trust antecedent with '(AAx)' [27]. After the initial coding process, we summarized the factors that influenced clients' trust in the ridesharing platform and developed a rigorous description on each type of trust.

Table 1. Results of the opening coding (portion)

\begin{tabular}{|c|c|c|c|}
\hline \multirow{2}{*}{ Original statement (interviews on clients) } & \multicolumn{3}{|c|}{ Coding Process } \\
\hline & Definition & Conceptualization & Categorization \\
\hline $\begin{array}{l}\text { I prefer drivers who are well-dressed and well- } \\
\text { mannered, or I will be upset(a1)...... I have never had } \\
\text { similar experience before so I am a little confused } \\
\text { about using this platform(a2). }\end{array}$ & $\begin{array}{l}\text { a1 Drivers' } \\
\text { personal traits } \\
\text { a2 Absence of } \\
\text { previous } \\
\text { experience }\end{array}$ & $\begin{array}{l}\text { A1 Categorization } \\
\text { process(a1) } \\
\text { A2 Illusions of } \\
\text { control(a2) }\end{array}$ & $\begin{array}{l}\text { AA1 } \\
\text { Cognition- } \\
\text { based } \\
\text { trust(A1) }\end{array}$ \\
\hline $\begin{array}{l}\text { I care about the punishment policy of invasion of } \\
\text { privacy, higher cost of crime means low rate of } \\
\text { crime(a3).....The ridesharing policy really matters } \\
\text { to me because I think that privacy protection is of } \\
\text { vital importance(a4). }\end{array}$ & $\begin{array}{l}\text { a3 Cost of } \\
\text { invasion of } \\
\text { privacy } \\
\text { a4 Privacy } \\
\text { protection policy }\end{array}$ & $\begin{array}{l}\text { A3 Cost of } \\
\text { crime(a3) } \\
\text { A4 Policy(a4) }\end{array}$ & $\begin{array}{l}\text { AA2 } \\
\text { Calculative- } \\
\text { based trust } \\
(\mathrm{A} 3, \mathrm{~A} 4)\end{array}$ \\
\hline $\begin{array}{l}\text { I will think about the firm reputation before I use a } \\
\text { new platform and application(a5)....... Maybe I would } \\
\text { check the drivers' working experience before I get } \\
\text { into his(her) car(a6). }\end{array}$ & $\begin{array}{l}\text { a5 Platform } \\
\text { reputation } \\
\text { a6 Working } \\
\text { experience }\end{array}$ & $\begin{array}{l}\text { A4 Previous } \\
\text { interactions and } \\
\text { familiarity(a5) }\end{array}$ & $\begin{array}{l}\text { AA3 } \\
\text { Knowledge- } \\
\text { based } \\
\text { trust(A4) }\end{array}$ \\
\hline $\begin{array}{l}\text { If the ordering process is just familiar to me and just } \\
\text { as it ought to be, I will accept the platform(a7)...... } \\
\text { really care about the reputation of the platform and } \\
\text { the firm. For example, if I know that the firm got the } \\
\text { investment of the Alibaba, I will feel at ease to use } \\
\text { the platform(a8)......Insurance from the platform } \\
\text { makes me feel comfortable to use the ridesharing } \\
\text { platform(a9). }\end{array}$ & $\begin{array}{l}\text { a7 Familiarity of } \\
\text { the ordering } \\
\text { process } \\
\text { a8 Third party } \\
\text { endorsement } \\
\text { a9 Third party } \\
\text { insurance }\end{array}$ & $\begin{array}{l}\text { A5 Situational } \\
\text { normality(a6) } \\
\text { A6 Structural } \\
\text { assurances(a7,a8) }\end{array}$ & $\begin{array}{l}\text { AA4 } \\
\text { Institution- } \\
\text { based } \\
\text { trust(A5, A6) }\end{array}$ \\
\hline $\begin{array}{l}\text { I don't think the drivers or platform will use my } \\
\text { personal information for others, I trust in } \\
\text { them(a10)...... I haven't think of the security before } \\
\text { and maybe I don't care that(a11). }\end{array}$ & $\begin{array}{l}\text { a10 Believe in the } \\
\text { platform and } \\
\text { drivers } \\
\text { a11 Don't care } \\
\text { about security }\end{array}$ & $\begin{array}{l}\text { A7 propensity to } \\
\text { trust the platforms } \\
(\text { a9,a10) }\end{array}$ & $\begin{array}{l}\text { AA5 } \\
\text { Personality- } \\
\text { based } \\
\text { trust(A7) }\end{array}$ \\
\hline
\end{tabular}

\section{Model and hypotheses}

According to the literature review and interview coding, we proposed the model shown in figure 2. Our model consists of a number of factors and antecedents that can affect clients' trust in the ridesharing platform in two stages, including personality-based beliefs, cognition-based beliefs and institution-based beliefs. These factors are verified as trust antecedents both in literature and in our research. We also draw upon the technology acceptance model (TAM) and rational choice theory (RCT) to investigate the dynamic development process of trust in two stages. After the coding analysis, we developed a comparison of the two-stage coding and find that perceived privacy and the security protection of clients plays an important role in the development of initial trust and ongoing trust, which is considered as a moderator in this research model. 


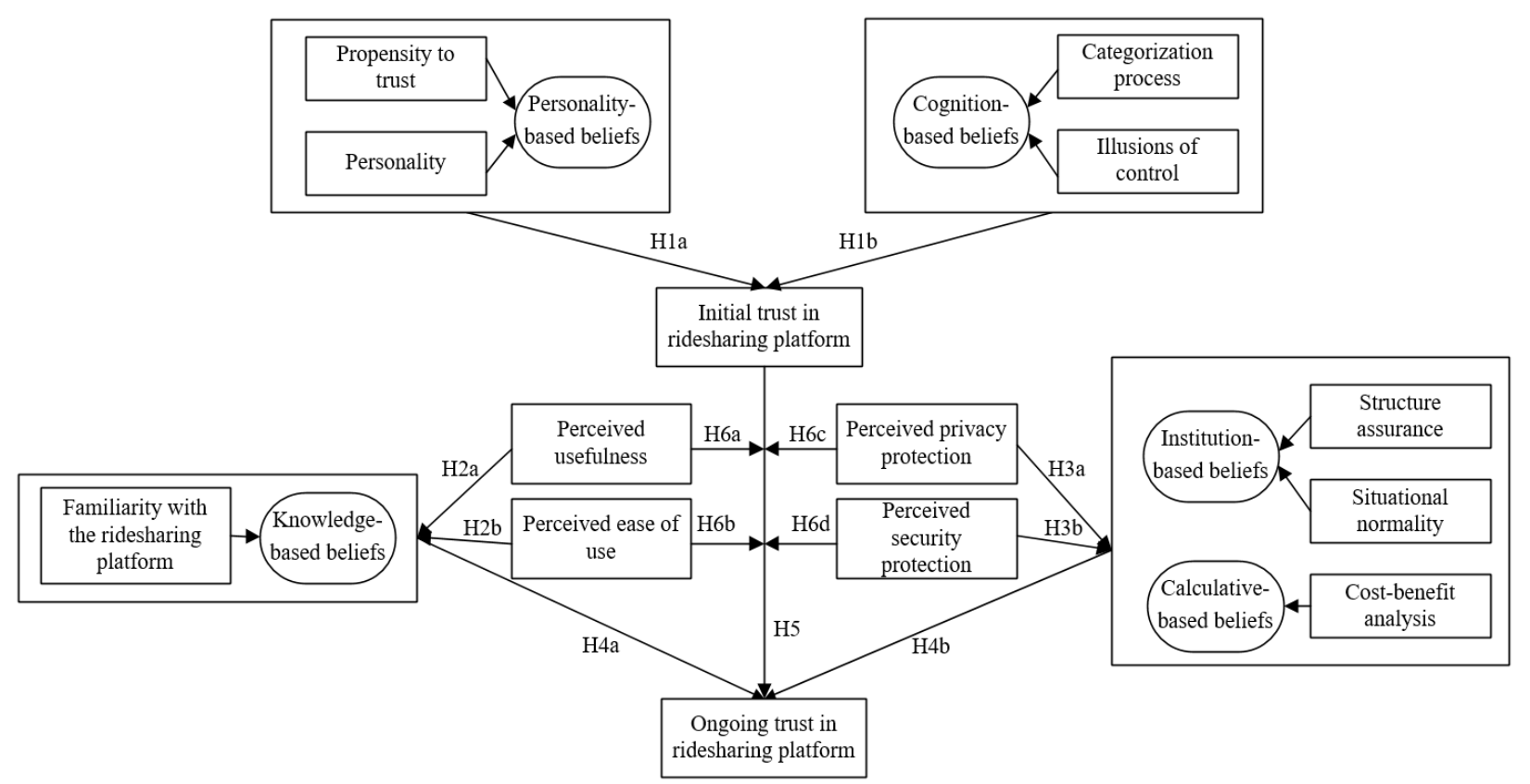

Figure 2. Research model of trust development in two stages

Initial trust is not based on any experience or firsthand previous experience [28]. As a result, the clients' personality and their propensity to trust, which constitute personality-based trust in this research, play an important role in the trust building process of the initial stage. According to the literature, clients' willingness to use something and their trust in a new platform sometimes depends on their first impression. Therefore, when people have never had prior first-hand experience with the ridesharing platform, they may observe the platform by observing cues that confirm the platform is trustworthy and build their initial trust on the platform [29]. Therefore, we hypothesize that:

H1a. Personality-based beliefs have a positive impact on clients' initial trust in a ridesharing platform.

H1b. Cognition-based beliefs have a positive impact on clients' initial trust in a ridesharing platform.

As clients have more interaction and user experience with the ridesharing platform, they may accumulate more trust-relevant knowledge and understanding of the rules of the platform [30], including when and how to enter their private location information or credit information. In addition, they may find that the ridesharing platform can largely reduce their time waiting for a bus or taxi and improve their efficiency, their perceived usefulness (PU) and perceived ease of use (PEOU) will positively impact clients' knowledge-based trust, which is based on clients' user experience and familiarity with the platform [31]. Therefore, we hypothesize that:

H2a. Perceived usefulness (PU) of the platform has a positive impact on clients' knowledge-based beliefs.

H2b. Perceived ease of use (PEOU) has a positive impact on clients' knowledge-based beliefs.

Perceived privacy protection refers to clients' perception of the likelihood that the platform will protect their private information collected during the transaction or trading process [32]. Perceived security protection refers to clients' perception that the platform will fulfill security requirements during the transaction process [33]. For example, when clients realize that there are some security features and protection mechanisms, including a security policy, a safe guarantee or protection in the ridesharing platform, they will obtain more assurance from the platform and their institution-beliefs will be built [34]. During our interview with the clients, many clients mention that policy on privacy protection in ridesharing platforms may enhance their beliefs that the ridesharing platform is under the supervision of the central government and their rights and interests are guaranteed.

In addition to the structural assurance brought to clients, the perceived privacy and security protection of the platform can also increase the cost of criminal 
behavior in use of the platform [35]. According to RCT, individuals are rational and once the cost of offending others' rights exceeds the benefit from deviant behavior [36], they will make rational choices and regulate their behavior. As a result, privacy or security from the government or the platform will have a positive impact on clients' calculative-based beliefs in the platform [37]. Therefore, we propose the following hypotheses:

H3a. Perceived privacy protection of clients has a positive impact on clients' institution-based beliefs and calculative-based beliefs.

H3b. Perceived security protection of clients has a positive impact on clients' institution-based beliefs and calculative-based beliefs.

After a long-term experience with the ridesharing platform, clients' trust develops to a new stage. In this ongoing stage, personality-based beliefs and cognitionbased beliefs will be less important to clients' trust in the platform [38]. Instead, different factors have proved to be the main factors that affect clients' trust in the platform at this stage. For example, after several times using the platform, clients become more familiar with the platform, and they will be more trusting of the platform, which means that the knowledge-based beliefs of clients can increase their level of trust during the ongoing stage [39].

Additionally, clients' institution beliefs in the platform resulting from the structural assurance and situational normality also will increase clients' ongoing trust in the platform [40]. Therefore, we propose the hypotheses that:

H4a. Knowledge-based beliefs have a positive impact on clients' ongoing trust in a ridesharing platform.

H4b. Institution-based beliefs and calculativebased beliefs have a positive impact on clients' ongoing trust in a ridesharing platform.

We consider initial trust as a very important antecedent of building ongoing trust. Based on positive feelings in previous user experience in the initial stage, people will be willing to have more interactions or trading in the future. Moreover, it has been shown in some literature that the trust relationship is robust over time [41], positive feelings in the initial stage will have a positive impact on feelings in the ongoing stage. Therefore, we propose following hypotheses:
H5. Clients' initial trust in the ridesharing platform has a positive impact on the level of their ongoing trust.

We believe that a high level of initial trust may lead to a high level of ongoing trust [42]. Moreover, since we take a dynamic view of trust development, it will be true that the dynamic process from the initial stage to the ongoing stage will vary in degree resulting from different factors.

Usefulness and ease of use are two key characteristics of the platform after several interactions with the ridesharing platform. These two factors were first proposed in the technology acceptance model (TAM). PU estimates clients' subjective assessment of the utility offered by the new IT. PEOU estimates the effort needed to learn and to utilize the new IT [43]. In this study, we postulate that the more utility clients can obtain from using the ridesharing platform, the more positive the effect will be in the dynamic process between initial trust and ongoing trust. In a similar way, PEOU has the same effect on trust in the two stages.

Moreover, when the government promulgates a privacy protection policy or security protection policy, the positive effect between trust in the two stages will increase, and the level of clients' ongoing trust will be higher. The following hypotheses are formulated:

H6a. Perceived usefulness (PU) of the platform has a moderating relationship between initial trust and ongoing trust.

H6b. Perceived ease of use (PEOU) has a moderating relationship between initial trust and ongoing trust.

H6c. Perceived privacy protection (PPP) of clients has a moderating relationship between initial trust and ongoing trust.

H6d. Perceived security protection (PSP) of clients has a moderating relationship between initial trust and ongoing trust.

\section{Conclusion and future research}

\subsection{Conclusion}

Trust development is vital to emerging business models. This research puts forward new insights in trust relationships in ridesharing. It distinguishes trust antecedents in different stages and investigates trust in a dynamic view. The purpose of this study is to investigate the antecedents of clients' trust in the sharing economy-driven ridesharing platforms and the 
dynamic development process of trust between initial and ongoing stages. In this research, we draw several preliminary conclusions based on the questions that we asked at the beginning of the study.

For the first research question we found that personality-based beliefs, cognition-based beliefs, calculative-based beliefs, institution-based beliefs, and knowledge-based beliefs are the main antecedents that lead to clients' trust in ridesharing platforms. Specifically, cognition-based beliefs and personalitybased beliefs are unique antecedents of initial trust, which are based on first impressions of the platform. Knowledge-based beliefs, calculative-based beliefs, and institution-based beliefs are unique antecedents of ongoing trust, which is built on the actual interactions with the platform.

For the second research question, we found that clients' initial trust in the ridesharing platform has a positive impact on their ongoing trust. In the dynamic process of trust development, the degree of perceived usefulness (PU), perceived ease of use (PEOU), perceived privacy protection (PPP), and perceived security protection (PSP) of clients have a moderating effect on the relationship between initial trust and ongoing trust. A high level of these moderators leads to deeper impact of trust development in two stages.

Theoretically, this study investigates the clients' trust in the ridesharing platform and provides a new viewpoint in ridesharing economy. Also, this study takes trust as a dynamic process from initial stage and ongoing stage, which is more suitable for the real status. As a result, this research contributes to the sharing economy research and the trust research in information systems. It also provides new directions for information communication technology and business collaboration research for development.

Practically, this research finds out that after a period of development of ridesharing platform and business environment, clients may be more familiar with the ridesharing platform. Their perceived feelings on the platform and government policy will influence their trust in the ongoing stage. As a result, for the online ridesharing company, more functions on clients' perceived security and privacy prediction should be enhanced. This study could also enhance communication for clients and the ridesharing platforms. Furthermore, it could help improve future business collaboration for drivers and platforms.

\subsection{Limitation and future research}

However, as this is ongoing research, there are still some limitations in this study. First, this current study only investigates the trust development process but doesn't take clients' real behavior outcomes and consumer behavior into consideration. Second, our data is limited as a result of time and financial constraints. Third, survey-based research to test the model should be considered in the future.

The development of information technology and the growth of Web2.0 has enabled the growth of online platforms that promote user-generated content, sharing and collaboration [44]. Future research could focus more on consumer behavior and ongoing willingness in the ridesharing platform. Moreover, more interviews need to be conducted and more data needs to be collected to further the investigation. In addition, survey could be used to test our research model.

\section{Acknowledgement}

The authors would like to thank National Natural Science Foundation of China (Grant No.71871061) for providing funding for part of this research.

\section{References}

[1] H.A. Posen, "Ridesharing in the Sharing Economy: Should Regulators Impose Uber Regulations on Uber", Iowa Law Review, 2015, pp. 405-434.

[2] P. Resnick, and R. Zeckhauser, "Trust Among Strangers in Internet Transactions: Empirical Analysis of EBay's Reputation System", The Economics of the Internet and Ecommerce, 2002, pp. 127-157.

[3] E. Ert, A. Fleischer, and N. Magen, "Trust and Reputation in the Sharing Economy: The Role of Personal Photos in Airbnb", Tourism Management, 2016. pp. 62-73.

[4] X. Cheng, S. Fu, and G. Yin, "Does Subsidy Work? An Investigation of Post-adoption Switching on Car-hailing Apps", Journal of Electronic Commerce Research (18:4). 2017, pp. 317-329.

[5] X. Cheng, S. Fu, and G.J. de Vreede, "Understanding Trust Influencing Factors in Social Media Communication: A Qualitative Study", International Journal of Information Management, (37:2), 2017, pp, 25-35.

[6] X. Cheng, S. Fu, and D. Druckenmiller, "Trust Development in Globally Distributed Collaboration: A Case of US and Chinese Mixed Teams", Journal of Management Information Systems, (33:4), 2016, pp. 978-1007.

[7] J.L. Wildman, M.L. Shuffler, E.H. Lazzara, S.M. Fiore, C.S. Burke, E. Salas, and S. Garven, "Trust development in swift starting action teams: A multilevel framework", Group \& Organization Management, 2012, (37:2): 137-170.

[8] D.M. Rousseau, S.B. Sitkin, R.S. Burt, and C. Camerer, "Not So Different After All: A Cross-discipline View of Trust", Academy of Management Review (23:3), 1998, pp. 393-404.

[9] F.D. Davis, R.P. Bagozzi, and P.R. Warshaw, "User Acceptance of Computer Technology: A Comparison of Two Theoretical Models", Management Science (35:8), 1989, pp. 982-1003.

[10] D. Gefen, E. Karahanna, and D.W. Straub, "Trust and TAM in Online Shopping: An Integrated Model", MIS Quarterly (27:1), 2003, pp. 51-90. 
[11] J. Mair, and G. Reischauer, "Capturing the Dynamics of the Sharing Economy: Institutional Research on the Plural Forms and Practices of Sharing Economy Organizations", Technological Forecasting and Social Change, 2017, pp. 1120.

[12] N. Luhmann, "Familiarity, Confidence, Trust: Problems and Alternatives", Trust: Making and Breaking Cooperative Relations, 2000, pp. 94-107.

[13] S.P. Shapiro, "The Social Control of Impersonal Trust", American Journal of Sociology (93:3), 1987, pp. 623-658.

[14] J. Hamari, M. Sjöklint, and A. Ukkonen, "The Sharing Economy: Why People Participate in Collaborative Consumption", Journal of the Association for Information Science and Technology (67:9), 2016, pp. 2047-2059.

[15] G.A Akerlof, "The Market for 'Lemons': Quality Uncertainty and The Market Mechanism", Uncertainty in Economics, 1978, pp. 235-251.

[16] G.F. Farris, E.E. Senner, and D.A. Butterfield, "Trust, Culture, and Organizational Behavior", Industrial Relations: A Journal of Economy and Society (12:2), 1973, pp. 144-157. [17] R.C. Mayer, J.H. Davis, and F.D. Schoorman, "An Integrative Model of Organizational Trust", Academy of Management Review (20:3), 1995, pp. 709-734.

[18] J.N. Lee, and B. Choi, "Effects of Initial and Ongoing Trust in IT Outsourcing: A Bilateral Perspective", Information \& Management 48.(2:3), 2011, pp. 96-105.

[19] M. Koufaris, and W. Hampton-Sosa, "The Development of Initial trust in an 0nline Company by New Customers", Information and Management (41:3), 2004, pp. 377-397.

[20] X. Cheng, and L. Macaulay, "Exploring Individual Trust Factors in Computer Mediated Group Collaboration: A Case Study Approach", Group Decision and Negotiation (23:3), 2014, pp. 533-560.

[21] L. Richardson, "Performing the Sharing Economy", Geoforum, 2015, pp. 121-129.

[22] H. Li, J. Zhang, and R. Sarathy, "Understanding Compliance with Internet Use Policy from the Perspective of Rational Choice Theory", Decision Support Systems (48:4), 2010, pp. 635-645.

[23] N. Leeper Piquero, M. Lyn Exum, and S.S. Simpson, "Integrating the Desire-for-control and Rational Choice in a Corporate Crime Context", Justice Quarterly (22:2), 2005, pp. 252-280.

[24] R. Paternoster, and S. Simpson, "Sanction Threats and Appeals to Morality: Testing a Rational Choice Model of Corporate Crime", Law and Society Review (1996): 549-583. [25] K. Newton, "Trust, Social Capital, Civil Society, and Democracy", International Political Science Review (22:2), 2001, pp. 201-214.

[26] W.K. Smith, "Dynamic Decision Making: A Model of Senior Leaders Managing Strategic Paradoxes", Academy of Management Journal (57:6), 2014, pp. 1592-1623.

[27] K.M. Eisenhardt, "Building Theories from Case Study Research", Academy of Management Review (14:4), 1989, pp. 532-550.

[28] L. Wu, and J.L. Chen, "An Extension of Trust and TAM Model with TPB in the Initial Adoption of On-line Tax: An Empirical Study", International Journal of Human-Computer Studies (62:6), 2005, pp. 784-808.
[29] D.J. McAllister, "Affect-and Cognition-based Trust as Foundations for Interpersonal Cooperation in Organizations", Academy of Management Journal (38:1) ,1995, pp. 24-59.

[30] H.F. Lin, "An Empirical Investigation of Mobile Banking Adoption: The Effect of Innovation Attributes and Knowledge-based Trust", International Journal of Information Management (31:3), 2011, pp. 252-260.

[31] F.D. Davis, "Perceived Usefulness, Perceived Ease of Use, and User Acceptance of Information Technology", MIS Quarterly, 1989, pp. 319-340.

[32] D.J. Kim, D.L. Ferrin, and H.R Rao, "A Trust-based Consumer Decision-making Model in Electronic Commerce: The Role of Trust, Perceived Risk, and Their Antecedents", Decision Support Systems (44:2), 2008, pp. 544-564.

[33] M. Ahuja, B. Gupta, and P. Raman, "An Empirical Investigation of Online Consumer Purchasing Behavior", Communications of the ACM (46:12), 2003, pp. 145-151.

[34] X. Cheng, S. Fu, and G.J. de Vreede, "A Mixed Method Investigation of Sharing Economy Driven Car-hailing Services: Online and Offline Perspectives". International Journal of Information Management, 41, 2018, pp. 57-64.

[35] T. Hirschi, "On the Compatibility of Rational Choice and Social Control Theories of Crime", The Reasoning Criminal. Routledge, 2017, pp. 105-118.

[36] A. Tversky, and D. Kahneman, "Rational Choice and the Framing of Decisions", Journal of Business ,1986, pp. S251-S278.

[37] T. Suh, "Exhibited Trust and Excessive Knowledge Specificity: A Competitive Altruism Hypothesis", Industrial Marketing Management 62, 2017, pp. 51-60.

[38] A.O. Al-Jaafreh, R. Al-Adaileh, A. Gill, A. Al-Ani, and Y. Alzoubi, "A Review of Literature of Initial Trust in EServices: The Case of Internet Banking Services in Jordanian Context", Journal of Electronic Banking Systems, 2014, 1.

[39] A.C. Lossie, and J. Green. "Building Trust: the History and Ongoing Relationships Amongst Dsd Clinicians, Researchers, and Patient Advocacy Groups", Hormone and Metabolic Research (47:5), 2015, pp. 344-350.

[40] X. Li, T.J. Hess, and J.S. Valacich, "Why Do We Trust New Technology? A Study of Initial Trust Formation with Organizational Information Systems", The Journal of Strategic Information Systems (17:1) ,2008, pp. 39-71.

[41] A. Jøsang, and J. Golbeck, "Challenges for Robust Trust and Reputation Systems", Proceedings of the 5th International Workshop on Security and Trust Management (SMT 2009), Saint Malo, France. 2009.

[42] E. Garbarino, and R. Slonim, "The Robustness of Trust and Reciprocity Across a Heterogeneous US Population”, Journal of Economic Behavior and Organization (69:3) ,2009, pp. 226-240.

[43] D.A. Adams, R. R. Nelson, and P.A. Todd, "Perceived Usefulness, Ease of Use, and Usage of Information Technology: A Replication”, MIS Quarterly, 1992, pp. 227247.

[44] J. Hamari, M.Sjöklint, and A. Ukkonen, "The Sharing Economy: Why People Participate in Collaborative Consumption". Journal of the Association for Information Science and Technology, (67:9), 2016, pp. 2047-2059. 